\title{
CULTURA, EDUCAÇÃO E ALTERIDADE NUMA PERSPECTIVA ANTROPOLÓGICA
}

\author{
CULTURE, EDUCATION AND OTHERNESS IN ANTHROPOLOGICAL PERSPECTIVE \\ CULTURA, EDUCACIÓN Y ALTERIDAD EN LA PERSPECTIVA ANTROPOLÓGICA
}

\author{
Senilde Alcântara Guanaes* \\ Doutora em Ciências Sociais - Antropologia UNICAMP | Brasil \\ E-mail: seguanaes@gmail.com
}

\begin{abstract}
REVISTA PEDAGÓGICA
Revista do Programa de Pós-graduação em Educação da Unochapecó | ISSN 1984-1566 Universidade Comunitária da Região de Chapecó | Chapecó-SC, Brasil Como referenciar este artigo: GUANAES, S. A. Cultura, educação e alteridade numa perspectiva antropolótica. Revista Pedagógica, Chapecó, v.16, n.32, p. 65-79, jan./jul. 2014.
\end{abstract}

RESUMO: Antropologia e Educação, disciplinas próximas em suas origens colonialistas, foram gradualmente distanciadas à medida que os processos culturais, dada a dinâmica e intersubjetividade destes, foram institucionalizando a Educação. Grosso modo, esses processos conferiram-lhe a árdua tarefa de sistematizar e transmitir um conjunto específico de saberes, experiências e conhecimentos que servem não apenas à formação do intelecto e do caráter dos indivíduos, como também à inserção e adaptação destes aos padrões de sociabilidade vigentes. Por outro lado, à Antropologia coube, de um modo geral, a análise e compreensão de grupos sociais normalmente divergentes e/ou alheios a tais padrões. $\mathrm{O}$ resgate da confluência entre as duas disciplinas, extremamente necessário nos dias atuais, implica em uma reflexão não apenas dos distintos paradigmas que as sustentam, como também dos seus objetos e campos de atuação, senão comuns, cada vez mais próximos. $\mathrm{O}$ texto traz algumas questões sobre alteridade e cultura, campo onde as duas disciplinas se cruzam e se disseminam.

PALAVRAS-CHAVE: Educação. Antropologia. Cultura. Alteridade.
ABSTRACT: Anthropology and Education, disciplines close in their colonial origins, were gradually moving away from each other as far as cultural processes, due to their dynamic and intersubjectivity, were institutionalizing the education, and roughly speaking, giving it an arduous task of systematizing and transmitting a set of specific knowledge, experience and expertise to serve not only of the individuals character and intellect formation as well as the insertion and adaptation of them to current standards of sociability. In the meantime Anthropology was assigned, in general, the analysis and understanding of usually divergent social groups and/or unrelated to such standards. The confluence redemption between the two disciplines, very necessary nowadays, implies a reflection on the different paradigms that underpin them as well as their goals and fields, increasingly common and closer. The text brings some questions about otherness and culture, a field where the two disciplines intersect and pollinate each other.

KEYWORDS: Education. Anthropology. Culture. Otherness. 


\footnotetext{
* Doutora em Ciências Sociais/Antropologia e Pós-doutora em Educação pela UNICAMP. Atualmente é Profa. Adjunta do curso de Graduação em Antropologia da Universidade Federal da Integração Latino Americana (UNILA).
}

\section{INTRODUÇÃO}

Enquanto a Antropologia ignorava as formas nativas ou populares de educação de suas crianças e jovens, a educação a eles dirigida procurava civilizá-los, tornando-os uma meia figura híbrida e marginalizada, 'nem ainda um índio e nem já um branco' (Brandão, 2009, p. 13).

Cada vez mais as nossas sociedades e culturas se hibridizam, se mesclam e se sobrepõem umas às outras, ou, visto por outro prisma, cada vez mais tem sido difícil modelar, uniformizar e "civilizar" esse processo. Nesse movimento, a Antropologia tem sido desafiada a decifrar esses enigmáticos processos culturais e conferir-lhes sentido, enquanto a Educação tem tido a função de mediadora desses processos. A educação, escolar ou não, tem ocupado um papel crucial na relação com o "outro", ora civilizatório e repressor das diferenças e da autonomia, ora formador e articulador dos movimentos políticos, religiosos, culturais e econômicos. Não sendo uma teórica da educação, permito-me apenas lançar um olhar antropológico e enviesado sobre os processos sociais que a educação abrange e envolve.

Como a questão central proposta nesta discussão parte do princípio de que não apenas as políticas educacionais, mas também as demandas econômicas e sociais que definem a agenda, o papel e o lugar da educação em cada sociedade e/ou grupo, conferindo-lhe um caráter contextual e local que extrapola os modelos educacionais e os padrões universais desses modelos, o objetivo é refletir sobre a atuação ou omissão dos processos educativos no contexto das sociedades contemporâneas, e não sobre os pressupostos disciplinares e epistemológicos do campo da educação. Entendendo os processos educativos, em todos os seus aspectos, como produtores, mas também produtos da cultura e das relações de alteridade.

O estudo das culturas e civilizações humanas, e os próprios conceitos que as fundamentam, são questões que têm sido legadas à disciplina antropológica desde as suas origens evolucionistas, mas que também dizem respeito à filosofia, numa dimensão mais ontológica, e à educação, numa perspectiva mais pragmática e recente, posto que entender a humanidade não apenas desafia a escola a reavaliar suas funções, modelos e métodos de tempos em tempos, como também a transforma em arena de debate e confronto das distintas formas de vida, cultura e existência presentes na sociedade. Ou seja, as escolas e os espaços educativos não escolares são pequenos protótipos da diversidade presente nas sociedades contemporâneas.

A reflexão entre Antropologia e educação, já realizada por vários pesquisadores que se dedicam ao tema há décadas, tornou-se fundamental e imperativa nos dias atuais, na tentativa de compreensão de como lógicas 
distintas de mundo podem resultar em formas variadas, mas também conciliáveis de existência e reprodução social. Se os processos educativos produzem cultura e ao mesmo tempo são produtos dela, por mais paradoxais e complexos que sejam esses processos é necessário concebê-los como parte indissociável da cultura. Caso contrário, não será possível entender o papel emancipador da educação nas sociedades atuais, caracterizadas como pluriculturais e complexas.

Gusmão (1997), assim como outros autores que discutem a educação a partir da relação entre as duas disciplinas, Educação e Antropologia (Dauster, 1997; Souza, 2006; Brandão, 2002 e 2009; Tosta, 2009; Santos e Seixas, s/d), nos alerta sobre as armadilhas presentes na interface e no diálogo entre esses dois campos teóricos, em que a cultura pode ser "entendida como técnica social de manipulação da consciência, da vontade e da ação dos indivíduos, com a finalidade de modelar as personalidades humanas dos membros do grupo social" (Gusmão, 1997, p. 7), ou seja, a cultura como instrumento e não como valor em si.

No entanto, não se trata de problematizar a cultura em si, tema amplamente estudado e debatido pela Antropologia desde os seus autores mais clássicos até os chamados pós-modernos; tampouco esse é um tema facilmente esgotável, especialmente em contraponto com outras áreas e temas. Trata-se de lançar algumas considerações que julgo relevantes a respeito da educação como produção de alteridade, ou seja, de produção do Outro, e a presença e formas de atuação desses Outros nos processos educativos. Em outras palavras, é a relação entre cultura, educação e produção de alteridade que nos interessa nesta reflexão.

Pensar a cultura como relação, como produtora e produto das relações sociais e como movimento e comunicação contínuos, é pensá-la enquanto alteridade, diferença e identidade, temas de natureza antropológica, mas que se impõem cotidianamente à educação e aos processos educativos de modo geral, incluindo aqui a produção do conhecimento. Refletir sobre esses processos exige, portanto, um exercício de desnaturalização dos processos sociais. Souza chama atenção para esse aspecto ao observar que:

Isso significa perceber que o conhecimento reside na alteridade, na criação de espaços para o novo e mesmo para o desconcertante, incluindo-se aí tudo aquilo que escapa à procura racional: os afetos, as surpresas e, com eles, a sensação de uma angustiante incompletude. Como suportar o caráter por vezes corrosivo dessa dor? Talvez pela consciência - ou pela esperança - de que ela possa nos fazer provar as delícias de um criativo fazer sentido. (Souza, 2007, p. 198) 
Refletir sobre a educação e as relações de alteridade, ambas mediadas pela cultura, exige um exercício contínuo de aproximação e estranhamento em relação aos padrões sociais vigentes. Implica também em lançar um olhar sensível para a vida e os saberes cotidianos, norteado pela autonomia e respeito às diferenças. Sem essa perspectiva atenta para os múltiplos princípios e valores dos grupos e coletivos sociais, queSegato (2006) chama de "comunidades morais", é difícil refletir sobre essas relações sem o risco de cair em modelos civilizatórios e monoculturais de educação e sociedade.

\section{EDUCAÇÃO COMO ALTERIDADE}

No campo da educação, seguramente a escola é o modelo privilegiado de ensino-aprendizagem. No entanto, sobretudo em sociedades pluriculturais, não é e nem deve ser o único, e talvez não seja também o mais importante instrumento de formação, transmissão e produção de conhecimento, visto que os processos de aprendizagem encontram-se por toda parte e cada vez mais singulares e atuantes, não apenas em espaços extraescolares, mas também dentro da própria escola, onde formas paralelas e normalmente espontâneas de sociabilidade e aprendizagem, que têm criado outros mundos dentro do espaço escolar, produzindo relações muitas vezes conflituosas e antagônicas com os modos formais de aprendizagem. Refiro-me, por exemplo, aos grupos de música, rap, rock, grafite e outras manifestações culturais que nascem nos pátios e imediações da escola.

O fato é que a produção de alteridade e da diferença se dá em todas as partes, e cada vez mais acentuadamente, extrapolando os muros da escola, da comunidade, das fábricas, sindicatos, cooperativas, associações, grupos artísticos, entidades religiosas, movimentos civis de luta etc. Em todos os lugares se produz, de maneira consciente ou não, técnicas e saberes, modos de ser, viver, fazer que escapam às normas, preceitos e modelos (Certeau, 1994). A alteridade, como processo contínuo e subjetivo de construção e desconstrução do outro, constitui e destitui espaços e sujeitos em um processo cada vez mais acelerado, difuso e disforme, produzindo sociedades mais heterogêneas em nível local/nacional, apesar da homogeneização produzida pelas e nas sociedades globais.

Não há novidade alguma em afirmar que os espaços de construção e circulação de saberes são múltiplos e variados; eles sempre existiram, seja para suprir a educação escolar, seja para suprir aquilo que ela não propiciava. $\mathrm{O}$ movimento de educação popular no Brasil, na década de 1960, revelou não apenas as deficiências da educação no País, mas também a elitização dos processos e espaços educativos, reforçando o caráter político, emancipatório e transformador da educação (Brandão, 2002; Freire, 2000). Com os movimentos de educação popular e os 
movimentos sociais, a educação ampliou a sua potência enquanto instrumento político de luta e de inversão da ordem dominante.

Mas o que torna esses espaços de produção de saber, chamados de informais, alheios e/ou marginais aos espaços oficiais de educação? O que separa o conhecimento apreendido na escola dos saberes experimentados nas ruas? Há uma produção significativa a respeito desse tema, e de modo geral, o conteúdo do conhecimento ensinado/ apreendido e a forma como é transmitido têm sido os principais aspectos ressaltados nessa discussão, conferindo um lugar ainda irrelevante e secundário aos indivíduos, suas referências culturais e seus sentidos de mundo. Dito de outro modo, o mundo vivido fora dos muros da escola, e que dificilmente transpõe esses muros, a não ser como revelia e desordem, torna-se invisível e/ou marginal quando expandido para o ambiente escolar. Esses sujeitos, quando inseridos no chamado sistema educacional formal, acabam sendo desintegrados das relações que os identificam, sejam elas de classe, gênero, étnicas, raciais, nacionais etc., que coloca em dúvida se a educação, como é concebida e praticada atualmente, contribui de fato para a emancipação, igualdade e justiça social.

Esse desenlace da educação dos experimentos, sensações e subjetividades do mundo vivido não apenas provoca o esvaziamento dos espaços tradicionais de aprendizagem, como também deteriora os seus sentidos, produzindo os vazios e as ausências que têm alimentado uma cultura da violência e de exclusão do outro, por um lado, e transformado outros lugares e vivências em experiências orgânicas e eficientes de conhecimento e de autonomia, por outro. Tomo como exemplo deste último, a circulação de saberes presentes nos movimentos sociais e de resistência, nos terreiros de candomblé, nas aldeias indígenas, nas cooperativas e associações trabalhistas e/ou identitárias, nas comunidades, nos espaços religiosos, nos movimentos culturais e outros tantos múltiplos e infindos lugares. Como dar conta de mediar essas alteridades para fora e para dentro do processo educativo é o grande desafio.

\section{EDUCAÇ̃̃O E ANTROPOLOGIA: A RECIPROCIDADE NECESSÁRIA}

Supondo que são os contextos culturais, políticos e econômicos que definem o papel e o lugar da educação, e que há entre os grupos sociais mais atrelados à cultura e à natureza uma intensa circulação e produção de saberes, não apenas saberes tradicionais, mas também aqueles que são reelaborados cotidianamente, é de suma importância e urgência fomentar uma discussão reflexiva, corajosa e crítica a respeito do papel da educação na colonização cultural e política das mentalidades na história das sociedades mundiais, sobretudo das "periféricas", como é o caso das sociedades latino-americanas. 
Não se trata de teorizar sobre a educação, como já foi dito, e nem de refletir sobre esses outros saberes tomando-os como processos informais, em oposição à escola. Ao contrário, nessa perspectiva propõe-se que a educação seja pensada como parte inerente e fundante das relações humanas e das culturas, enfatizando a integração, a reciprocidade e o diálogo entre os saberes. Não há dúvidas de que a crise da educação ocidental é a crise de um sistema-mundo que se pretende homogêneo, e que se recusa a reconhecer as tantas outras dimensões dos saberes. A educação é uma extensão da cultura, da política e dos conflitos sociais; é inviável pensá-la isoladamente, e a partir de um referencial epistêmico disciplinar, portanto, é urgente e indispensável pensá-la à luz da Antropologia, não apenas porque a disciplina, desde a sua origem, se dedica à compreensão da constituição e transmissão da cultura, mas, sobretudo, pela reciprocidade e interdependência dos temas aos quais se dedicam.

A educação elevada à sua potência, ao lado da Antropologia contemporânea, que vem tentando lutar pela "descolonização" de seus conceitos e categorias explicativas, buscando cada vez mais extrai-los dos seus contextos empíricos particulares e não de teorias descontextualizadas dos seus locais, são campos disciplinares privilegiados para a compreensão e o entendimento da cultura, lugares de onde se pensa e se vive a alteridade, sobretudo quando se trata de entender os enigmas desse complexo sistema de códigos, símbolos, linguagem e vida, chamado cultura - autogeradora de um "fazer reflexivo e crítico por vezes chamado educação” (Gusmão, 1997).

No entanto, Gusmão (1997), assim como outros autores que discutem a abordagem entre as duas disciplinas (Dauster, 1997; Souza, 2006; Santos e Seixas, s/d; Brandão, 2002 e 2009) nos alerta também sobre as prováveis armadilhas presentes na interface desses dois campos teóricos, em que a cultura pode ser "entendida como técnica social de manipulação da consciência, da vontade e da ação dos indivíduos, com a finalidade de modelar as personalidades humanas dos membros do grupo social" (Gusmão, 1997, p. 7).

AAntropologiaeaEducaçãosãocamposdisciplinares distintos, embora complementares e recíprocos, por isso, não raramente, são colocados em oposição, e depreciados quando confrontados em suas funções. No entanto, as relações e experiências proporcionadas pela "cultura" têm exigido maior diálogo e uma nova relação entre os dois campos disciplinares, uma vez que a cultura pressupõe relação, alteridade e mediação entre distintos mundos, racionalidades e saberes. Pensemos em exemplos concretos, como o protagonismo de grupos locais na demanda pelos direitos de uso e ocupação dos seus territórios de origem. Sem reconhecer os seus saberes, lógicas e racionalidades 
específicas, não é possível reconhecer a autonomia e a capacidade política desses grupos, o que, de certa maneira, é uma forma de negar esses direitos.

Mas é preciso chamar atenção para o fato de que estudar a cultura exclusivamente em suas relações étnicas e identitárias - a "cultura" tomada comoidentidadefixa ecomo "fronteiras" de pertencimento -, perspectiva recorrente na história da Antropologia, pode incorrer na cristalização de categorias conceituais que, no lugar de entender o objeto, o aprisionam, limitando sua compreensão e análise. Para escapar das armadilhas conceituais é necessário colocar os sujeitos empíricos e as experiências vividas por estes acima das categorias explicativas. Colocar os sujeitos empíricos em foco significa, por exemplo, compreender as formas como os grupos sociais têm se apropriado de instrumentos políticos e jurídicos que ultrapassam as fronteiras étnicas, identitárias e de classe.

A cultura compreendida então como movimento e mediação permite observar e analisar as relações de alteridade que não estão circunscritas aos domínios de uma disciplina, ou de um campo temático, tampouco a categorias analíticas específicas, que sequer estariam limitadas ao campo da Antropologia, embora seja atualmente a disciplina mais instrumentalizada para lidar com o contínuo e intenso movimento e fluidez da alteridade. Tosta (2009) relata como o trabalho de campo nos coloca em constante relação com a alteridade, dando-nos a oportunidade de "aprender" com ela. O campo, para o antropólogo, é uma constante relação de apreensão e aprendizagem do(s) mundo(s) que se pretende(m) compreender.

Observar o outro a partir de dentro, ou melhor, tentar fazê-lo, implica em questionar as próprias formas de compreensão e análise. Em um nível mais profundo, implica na crítica e desconstrução do próprio campo de conhecimento. Souza (2007), ao analisar a alteridade desde o campo da psicologia até o campo antropológico, descreve essa inquietude da seguinte forma:

Isso significa perceber que o conhecimento reside na alteridade, na criação de espaços para o novo e mesmo para o desconcertante, incluindo-se aí tudo aquilo que escapa à procura racional: os afetos, as surpresas e, com eles, a sensação de uma angustiante incompletude. Como suportar o caráter por vezes corrosivo dessa dor? Talvez pela consciência - ou pela esperança - de que ela possa nos fazer provar as delícias de um criativo fazer sentido. (Souza, 2007, p. 198)

As complexas relações nas sociedades contemporâneas, sejam pautadas pelo discurso da interculturalidade no âmbito das leis e dos princípios morais, sejam simplesmente confrontadas com a inevitável coexistência de distintas culturas, têm imposto 
um desafio permanente de compreensão das fronteiras e das contiguidades destas a todas as áreas e campos do conhecimento, mas, em especial, ao campo da Antropologia e da Educação, não apenas pela aproximação empírica entre os dois campos, mas pela aproximação demandada pelos seus sujeitos, que veem na educação uma forma de emancipação social, em alguns casos, e de preservação da cultura, em outros.

Cada vez mais grupos sociais distintos, como caboclos, caiçaras, ribeirinhos, pescadores, indígenas etc., "tradicionais" ou não, requisitam formas mais inclusivas e menos desiguais de acesso à educação. A educação é vista não apenas como forma de ascensão social e de empoderamento, mas também como uma forma de agenciar as suas demandas culturais, étnicas e identitárias, como é o caso das populações afrodescendentes e indígenas, que diferente dos grupos sociais citados mais acima, lutam não apenas pelo direito à educação, mas, sobretudo, por uma educação que valorize e respeite seus princípios culturais.

Nessa perspectiva, quanto mais a educação é reivindicada como instrumento político de fortalecimento e reprodução da cultura, mais a Antropologia necessita de um diálogo orgânico e crítico com o campo da Educação. Por outro lado, concomitantemente, se pensarmos no nível de complexidade das sociedades contemporâneas, com os seus múltiplos e integrados afluentes culturais, veremos que, além de servir à cultura, a Educação necessita de um aparato antropológico para a compreensão do mundo no qual está inserida. Ou seja, ao mesmo tempo que atende demandas culturais específicas, a escola precisa fazer sentido para todos os mundos que a ocupam. Para esses tantos mundos que frequentam as escolas, "a educação só é possível como prática antropológica” (Tosta, 2009, p. 17).

Pensando na reciprocidade entre os dois campos, alguns paradigmas formalmente conhecidos como antropológicos podem e devem ser pensados para e pelo campo da Educação, pela relação que estabelecem no mundo real, afinal, os nossos objetos de interesse não têm fronteiras disciplinares, nós é que as criamos a partir dos nossos interesses e olhares. Tanto para a Antropologia, em seu esforço de entender e explicar os grupos sociais e suas formas distintas de criar e dar sentido ao mundo, quanto para a Educação, com sua missão de construir mecanismos de difusão e reprodução desses distintos mundos e saberes, ainda que seja a educação hegemônica que elege um mundo em detrimento de outros, o campo de semeadura e colheita é o mesmo: a produção e o entendimento do mundo a partir de formas específicas de atuação e compreensão.

Dito de outra maneira, o modo como a Antropologia se relaciona com os grupos sociais que pesquisa, seus métodos de compreensão destes, seus conceitos e categorias para explicá-los ao mundo, servem também para a relação 
do educador com esse "outro", o educando, visto que, no campo etnográfico ou na escola, o que está em jogo são as relações permeadas pelo estranhamento, pela perplexidade e descobertas, pela reflexão de si em relação ao “outro", em síntese, o que está em jogo é a aprendizagem de um outro "mundo".

$\mathrm{Na}$ Antropologia, as novas e intensas configurações culturais têm provocado a aproximação com várias disciplinas em função do crescimento político do campo da "cultura" e da pluralidade cultural, que têm produzido novas barreiras e destruído outras, aproximado lugares, pessoas e instituições, ao mesmo tempo, que os fragmentam e os segregam. A compreensão da cultura nos dias atuais transborda então para muitos outros campos: médico, jurídico, ambiental, político, educacional, biológico, não poupando nem mesmo os próprios grupos sociais - em suas associações, cooperativas, movimentos políticos etc. - que discutem, utilizam e se reapropriam do conceito de "cultura", este com aspas (Carneiro da Cunha, 2009), seja em função das suas demandas políticas, seja pela reflexão do seu próprio ethos.

Existe uma espécie de fronteira aquém da qual é preciso estar para simpatizar com o mito, e além da qual é preciso estar para estudá-lo. Temos a sorte de viver perto dessa faixa fronteiriça e de poder passar e repassála à vontade. (Tylor apud Laplantine, 2007, p. 186).

A Antropologia, assim como a Educação enquanto cultura, para além de lugares, são fronteiras, visto que se encontram não na identidade, na etnia ou em contextos sociais específicos, e sim na mediação. Seja no encontro etnográfico, seja nas relações socioeducativas, escolares ou não, é o movimento até o "outro" que traduz e confere sentido às duas disciplinas, e é esse movimento ou mediação que envolve a construção da alteridade.

\section{ALTERIDADESEM MOVIMENTO: A CULTURA COMO MEDIAÇÃO}

A cultura como mediação e comunicação e, portanto, linguagem e movimento, aproximam os campos da Antropologia e Educação. Ambas estariam situadas em uma espécie de "terceira margem" na intersecção que fragmenta e ao mesmo tempo conecta os distintos grupos sociais, daí a necessidade da Antropologia também se colocar como a ciência da alteridade e da mediação, e não da "cultura", pura e simplesmente. Laplantine (2003) também fala sobre a Antropologia como a disciplina da "comunicação dos seres e das culturas”, onde a fixação em uma margem, em detrimento de outras, levaria ao fim da especificidade antropológica e da capacidade interpretativa da disciplina.

A cultura tornou-se um lugar absoluto e paradoxalmente relativo de explicação, experiência e 
encontro - um lugar de comunicação e meta-linguagem por um lado (Carneiro da Cunha, 2009) e da práxis e da política por outro. Essa explosão cultural, ao mesmo tempo que valida a Antropologia como ciência do "outro", ou seja, como ciência intérprete e tradutora de outras culturas, a coloca em uma relação conflituosa com outros campos e segmentos, especialmente o campo da política, o que volta a enfraquecer a relação com a Educação, se pensarmos que a Educação é uma das instituições que sustenta o projeto hegemônico de construção do estado nação.

A visão da cultura, de uma cultura, desta cultura, como um consenso em torno de elementos fundamentais - concepções comuns, sentimentos comuns, valores comuns - parece muito pouco viável, diante de tamanha dispersão e desarticulação; são as falhas e fissuras que parecem demarcar a paisagem da identidade coletiva. (Geertz, 2001, p. 219).

Se a cultura fosse um "consenso" em torno de idéias, valores e sentimentos comuns, a alteridade seria o confronto entre distintos consensos postos todo o tempo em relação e movimento. Afinal, são várias formas de ver o mundo, todas pressupondo uma "verdade", e desejando - ou sendo obrigadas a - "se comunicar" a partir de interesses e experiências radicalmente distintas. Ou seja, a alteridade, nesse sentido, é o lugar onde se quer chegar, mas não necessariamente se alcança. Sobre esse aspecto, Lévi-Strauss escreve:

Somos passageiros desses trens que são nossas culturas, cada qual se movendo em seus trilhos próprios, com sua própria velocidade e em sua própria direção. Os trens que correm lado a lado, indo em direções similares e com velocidades não muito diferentes da nossa, são-nos ao menos razoavelmente visíveis, quando os olhamos de nossos compartimentos. Mas os trens que estão em trilhos oblíquos ou paralelos, indo em direção oposta, não o são. Percebemos apenas uma imagem vaga, fugaz e quase não identificável, em geral apenas uma mancha momentânea em nosso campo visual, que não traz nenhuma informação sobre si mesma e meramente nos irrita, porque interrompe nossa plácida contemplação da paisagem que serve de pano de fundo para nossos devaneios (Lévi-Strauss apud Geertz, 2001, p. 75).

Lévi-Strauss, com base na teoria estruturalista, oferece um esquema lógico para pensar as sociedades e a cultura como trens em movimento, mas com linhas férreas e vagões bem rígidos e definidos, que seriam as estruturas. Nessa perspectiva seria impossível atravessar as fronteiras do outro. Mas tomando a citação como metáfora: seria possível sair de um trem em movimento e entrar em outro trem? Seria mesmo possível conhecer profundamente o 
outro sem a morte do que somos? Ou tudo que pensamos conhecer sobre o outro são "miragens"? (Guanaes, 2007). São perguntas que a Antropologia precisa fazer, não à procura de respostas, mas em busca de mais perguntas. São as indagações que fazem operar os sentidos da nossa cultura em relação às outras.

A cultura só pode ser o lugar da mediação e do encontro quando busca não privilegiar nem o ponto de vista do observador e nem o do observado; o primeiro seria o etnocentrismo cego orientando o olhar sobre o outro, sobre o vagão que passa em direção oposta; o segundo seria uma idealização do outro e não o que ele de fato é, porque quando postos em relação, observador e observado interagem construindo alteridades específicas àquele encontro. Alteridades permeadas de diferenças, semelhanças, conflitos, relações de poder, status, que revelam, muitas vezes, a opressão e a desigual influência que um mundo exerce sobre o outro.

Para promover o "encontro" entre as distintas culturas, para instrumentalizar a mediação cultural, a Antropologia deve estar no meio: entre o ponto de vista do observador e o do observado, ela deve ser "uma prática que surge em seu limite, ou melhor, em sua intersecção" (Laplantine, 2007, p. 194). Mas esse encontro ou essa "intersecção" não acontece sem estranhamento, sem a "perplexidade provocada pelo encontro" (idem, 2007, p. 21); tal reação é comum a todas as culturas humanas, em outras palavras, todas as sociedades humanas produzem cultura(s) e produzem diferenças, é próprio dos grupos sociais acreditarem que aquilo que produzem é sempre mais lógico, racional e humano em comparação com os outros.

Mas se formos estruturalistas o bastante, podemos pensar a Antropologia como "um conjunto variável de narrativas sobre as 'miragens' do 'outro', ou melhor, sobre as miragens que traduzimos do 'outro"' (Guanaes, 2007, p. 482). O que buscamos entender no outro está misturado às nossas próprias experiências, por isso a Antropologia não pode se pretender uma ciência imparcial, aliás, qual ciência seria de fato imparcial, quando os resultados dela são produtos e produtores da vida e das formas de organização do mundo?

Essas questões servem para pensar uma Antropologia como mediadora cultural e política entre a práxis e a prática (Hall, 2003), e ressignificar as atribuições da pesquisa antropológica para além das suas teorias. Não que a disciplina demande esse papel e essas responsabilidades, mas simplesmente pelo fato de os seus sujeitos-objetos reivindicarem essa "mediação", assim como reivindicam o acesso ao conhecimento. O trabalho do antropólogo depende de "uma articulação adequada com o ponto de vista dos sujeitos da pesquisa" (Cardoso de Oliveira, 2008, p. 10). 
Essa mediação, cada vez mais assumida pela Antropologia, não é novidade em algumas áreas de estudo, como na etnologia, onde os antropólogos se posicionavam como intérpretes e muitas vezes representantes e defensores de determinados grupos étnicos.

É antiga também a prática de mediação desempenhada pelo antropólogo, que cria formas de tradução e concertação entre partes que comungam tradições diversas, concepções de mundos substancialmente diferentes e muitas vezes línguas díspares. Assim, foi lembrado por um participante que a justiça espera que o antropólogo seja capaz de atuar tanto junto aos índios quanto junto aos posseiros, isto é, espera-se que o antropólogo demonstre a habilidade em evidenciar as lógicas em conflito. (Silva, 2008, p. 15).

O debate sobre mediação, cultura e alteridade tem sido extremamente acirrado pelas guerras culturais (Hall, 2003; Said, 2003; Bhabha, 1998; Boaventura, 1997; Canclini, 1997), pelo embate entre racionalidades e políticas distintas, pela mundialização da economia e da cultura (Ortiz, 1999), e nos últimos tempos, pelos movimentos transnacionais com demandas que vão desde questões étnicas, até sexuais, de gênero, religiosas, ambientais, territoriais etc. Todas elas atravessadas pelo campo simbólico e explícito da violência.

O que parece estar muito evidente em todas as partes do mundo é a coexistência, habitualmente conflituosa e desigual, entre grupos culturais distintos e/ou distintas lógicas de mundo e as mais variadas maneiras de operálas. Entre essas lógicas, relações econômicas, políticas, religiosas, enfim, inúmeros campos de poder, definem as que devem ser predominantes e hegemônicas em detrimento de outras. O fato é que as lógicas permanecem coexistindo, independente de serem aceitas ou não. É isso que faz o mundo "multicultural", a coexistência e sobreposição de mundos.

Multicultural é um termo qualificativo. Descreve as características sociais e os problemas de governabilidade apresentados por qualquer sociedade na qual diferentes comunidades culturais convivem e tentam construir uma vida em comum, ao mesmo tempo em que retêm algo de sua identidade "original". Em contrapartida, o termo "multiculturalismo" é substantivo. Refere-se às estratégias e políticas adotadas para governar ou administrar problemas de diversidade e multiplicidade gerados pelas sociedades-multiculturais. (Hall, 2003, p. 52).

O multiculturalismo, em diferentes níveis, discute e propõe mecanismos políticos e jurídicos, em suma, institucionais, primeiro de reconhecimento desses 
mundos, segundo, de organização e engendramento destes nas sociedades nacionais, de modo a atender as suas especificidades e, ao mesmo tempo, garantir seus direitos e sua autonomia junto aos demais segmentos da sociedade civil. Uma missão complexa e mal resolvida em todos os países, posto que o reconhecimento e a validação dos direitos desses grupos ainda são mensurados por noções essencializadas de "raça", ancestralidade, etnia, "tradição" e cultura, produzindo perigosas armadilhas em torno da identidade e do reconhecimento da diferença - uma vez que as especificidades são reconhecidas e aceitas, elas próprias se transformam em "ciladas" para a discriminação e a violência contra essas minorias (Pierucci, 1990).

De todo modo, levantar o incansável debate sobre a cultura como mediação, empreitado pelos estudos culturais, não facilita o entendimento sobre como pessoas "comuns", na contramão de uma ordem totalitária e alheia aos seus modos de vida, conseguem se articular cotidianamente, $\mathrm{e}$ às vezes silenciosamente, em torno de especificidades que desconhecem fronteiras, pois são, ao mesmo tempo, territoriais, ambientais, culturais, étnicas, sexuais, políticas, e outras tantas, que não podem, portanto, ser compreendidas a partir de apenas uma dimensão, mas de várias. É uma questão para abrir e não para fechar a reflexão aqui proposta.

\section{REFERÊNCIAS}

BHABHA, Homi K. O Local da Cultura. Belo Horizonte: UFMG, 1998.

BENEDICT, Ruth. Padrões de Cultura. Lisboa: Ed. Livros do Brasil, s/d.

BOAS, Franz. Antropologia Cultural. Franz Boas. Celso Castro (org.). Rio de Janeiro: Jorge Zahar , 2004.

SANTOS, Boaventura de Sousa. Por uma concepção multicultural de direitos humanos. Lua Nova, 39, 1997.

BRANDÃO, Carlos Rodrigues. "Algumas palavras sobre a cultura e a educação”. In ROCHA, Gilmar; TOSTA, Sandra Pereira (orgs.). Antropologia e Educação. Belo Horizonte: Autêntica Editora, 2009, p. 11-16.

CANCLINI, Néstor García. Culturas Híbridas - estratégias para entrar e sair da modernidade. São Paulo: EDUSP, 1997.

CARVALHO, José Murilo de. Cidadania no Brasil. Rio de Janeiro: Civilização Brasileira, 2001.

CERTEAU, Michel de. A invenção do cotidiano I: artes de fazer. Petrópolis: Vozes, 1994.

DAUSTER, Tania. Um outro olhar: Entre a Antropologia e a educação. Cadernos CEDES, vol. 18, n. 43, 1997. 
ELIAS, Norbert. O Processo Civilizador. Rio de Janeiro: Jorge Zahar, 1990.

GEERTZ, Clifford. A Interpretação das Culturas. Rio de Janeiro: Zahar, 1978.

GIDDENS, Anthony. A constituição da sociedade. São Paulo: Ed. Martins Fontes, 1988.

As conseqüências da modernidade. São Paulo: Editora da UNESP, 1991.

GOHN, M. da G. Movimentos sociais e educação. $4^{\mathrm{a}}$. ed. São Paulo: Cortez, 2001.

GUANAES, Senilde Alcântara. Nas Miragens do Outro: Encontro etnográfico e questões de alteridade no romance Nove Noites. Revista Habitus: Goiânia, vol. 5, $\mathrm{n}^{\circ}$ 2, p. 481-490, jul./dez. 2007.

GUSMÃO, Neusa M. Antropologia e educação: origens de um diálogo. Cadernos CEDES, n. 43, p. 8-25, 1997.

. "Os desafios da diversidade na escola". In: GUSMÃO, Neusa M. (Org.). Diversidade, cultura e educação: olhares cruzados. São Paulo: Biruta, 2003. p. 83-105.

HALL, Stuart. A identidade cultural na pós-modernidade. Rio de Janeiro: DP \&A. 2003.

IANNI, Octávio. Revolução e Cultura. Rio de Janeiro: Civilização Brasileira, 1983.

KUPER, Adam. Cultura: a visão dos antropólogos. Bauru: EDUSC, 2002.

LARAIA, Roque de Barros. Cultura: um conceito antropológico. Rio de Janeiro: Jorge Zahar Editor, 2000.

LÉVI-STRAUSS, Claude. Raça e Cultura. Antropologia Estrutural II. Rio de Janeiro: Tempo Brasileiro, 1976.

ORTIZ, Renato. Cultura Brasileira e Identidade Nacional. São Paulo: Ed. Brasiliense, 1985.

PIERUCCI, Antônio Flávio. Ciladas da diferença. Tempo Social: Revista Sociologia USP, São Paulo, 2(2), p. 7-33, 2.Sem. 1990.

SAID, Edward. Cultura e Política. São Paulo: Boitempo Editorial, 2003.

SANTOS, Boaventura de Sousa. Renovar a teoria crítica e reinventar a emancipação. São Paulo, Boitempo, 2007.

SEGATO, Rita Laura. Antropologia e Direitos Humanos: alteridade e ética no movimento de expansão dos direitos universais. Rio de Janeiro: Revista Mana, 2006, p. 207-236. 
SOUZA, Mauricio Rodrigues de. Experiência do outro, estranhamento de si: dimensões da alteridade em Antropologia e psicanálise. São Paulo, 2007. Doutorado (Doutor em Psicologia). Instituto de Psicologia da Universidade de São Paulo - USP.

SOUZA, Mauricio Rodrigues de. Por uma educação antropológica: comparando as idéias de Bronislaw Malinowski e Paulo Freire. Revista Brasileira de Educação, v. 11, n. 33, p. 487 - 564, set./ dez., 2006.

VALENTE, Ana Lúcia. Conhecimentos antropológicos nos parâmetros curriculares nacionais: para uma discussão sobre a pluralidade cultural. In: GUSMÃO, Neusa M. (Org.). Diversidade, cultura e educação: olhares cruzados. São Paulo: Biruta, 2003. p. 17-46. 